\title{
Evaluation of Angiogenic Potential of 1-Monocaproin Using Chick Chorioallantoic Membrane Assay
}

Palaniappan Maheswari ${ }^{1, *}$, Kasthuri Revathi ${ }^{2}$

${ }^{1}$ Department of Biotechnology, Sathyabama University, Chennai, India

${ }^{2}$ Department of Zoology, Ethiraj College, Chennai, India

*Corresponding author: Maheswari P, Research Scholar, Department of Biotechnology, Sathyabama University, Jeppiaar Nagar, Rajiv Gandhi Road, Chennai 600119 , Tamil Nadu, India, Tel: 9144 25504536/91 44 45583992; E-mail: maheswari.p1966@gmail.com

Received: Apr 24, 2017; Accepted: Jun 12, 2017; Published: Jun 27, 2017

Copyright: (C) 2017 Maheswari P. This is an open-access article distributed under the terms of the Creative Commons Attribution License, which permits unrestricted use, distribution, and reproduction in any medium, provided the original author and source are credited.

\begin{abstract}
1-Monocaproin, a 1-monoacylglycerol, was synthesized with the reaction of glycidol by chromium-caproic fatty acid complexes and was found to be amphiphilic in nature. Synthesized 1-monocaproin was characterized by thin-layer chromatography, and the residual chromium was analyzed using inductively coupled plasma mass spectroscopy. Vascular endothelium growth factor (VEGF)-mediated angiogenesis pathways are being targeted for the development of novel drugs suitable for inhibition or stimulation of angiogenesis in various pathologies. In the chicken egg Chorioallantoic membrane (CAM) assay, 1-monocaproin exhibited VEGF-induced neovascularization in a dose-dependent manner. Synthesized 1-monocaproin was found to show the angiogenic effect at a dose concentration equivalent to VEGF at $1,000 \mathrm{ppm}$. The results thus suggest that 1-monocaproin should be considered as a useful drug candidature targeting angiogenesis in coronary artery disease, stroke, and postsurgical therapy.
\end{abstract}

Keywords: 1-Monocaproin; Chorioallantoic membrane assay; Vascular endothelium growth factor; Angiogenesis

\section{Introduction}

Blood vessels constitute the first organ in the embryo and form the largest network in our body but, sadly, are also often deadly. Upon dysregulation, the formation of new blood vessels contributes to numerous malignant, ischemic, inflammatory, infectious, and immune disorders. Neovascularization can be understood as the growth of new capillary blood vessels in the body and is an important natural process that helps in healing and reproduction. The body controls neovascularization by producing a precise balance of growth and inhibitory factors in healthy tissues. When this balance is disturbed, the result is either too much or too little angiogenesis. The abnormal growth of blood vessels, either excessive or insufficient, is now recognized as a "common denominator" underlying many deadly and debilitating conditions, including cancer, skin diseases, age-related blindness, diabetic ulcers, cardiovascular disease, stroke, and many others [1]. Molecular insights into these processes are being generated at a rapidly increasing pace, offering new therapeutic opportunities that are currently being evaluated. It represents an excellent tool for the treatment of deregulated angiogenesis-based cardiovascular diseases. It is a potent physiological process that underlies the natural manner in which our bodies respond to a diminished blood supply to vital organs, namely, the production of new collateral vessels to overcome the ischemic state [2]. A large number of preclinical studies have been performed with protein, gene, and cell-based therapies in animal models of cardiac ischemia as well as models of perpheral arterial diseases. Administration of a particular growth factor to stimulate angiogenesis in the affected tissues (or) organ and the protein therapy with single protein agent were not viable options to treat ischemic cardiovascular diseases [3]. Therapeutic angiogenesis is the method of stimulation of angiogenesis where it is required but lacking. This technique is used to replenish the blood supply to chronic wounds to speed healing and to prevent unnecessary amputations. New research also suggests that this approach can also be used to save limbs afflicted with poor circulation and even oxygen-starved hearts [4]. Therapeutic angiogenesis may even help to regenerate damaged (or) lost tissues in ways that were previously considered impossible such as with nerves and brain tissues. The modern clinical application of the principle of angiogenesis can be divided into two main areas: antiangiogenesis therapies with which angiogenesis research began and proangiogenic therapies [5]. Antiangiogenic therapies are being used to fight cancer and malignancies that require an abundance of oxygen and nutrients to proliferate. Proangiogenesis therapy is being explored as an option to treat cardiovascular diseases. One of the first applications of proangiogenic methods in humans was a German trial using fibroblast growth factor-1 (FGF-1) for the treatment of coronary artery diseases. Clinical research in therapeutic angiogenesis is ongoing for a variety of diseases like coronary artery diseases, peripheral arterial diseases, and wound-healing disorders [6]. The proangiogenesis therapies can be differentiated into three categories, namely, (i) protein therapy, (ii) gene therapy, and (iii) cell-based therapy, which involves the implantation of specific cell types. Other than the above three therapies, there are a few therapies only used to induce angiogenesis. Vascular endothelium growth factor (VEGF)-mediated angiogenesis pathways are being targeted for development of novel drugs suitable for inhibition or stimulation of angiogenesis in various pathologies [7]. The signaling system that regulates proliferation and migration of endothelial cells during angiogenesis is mediated via key mitogen factor, namely, VEGF. There remains an urgent need to develop strategies to more rapidly, inexpensively, and accurately assess the proangiogenic and antiangiogenic activities of new biologic factors and putative therapeutic agents [8]. The chick embryo Chorioallantoic membrane (CAM) is an extra embryonic membrane that serves as a gas exchange surface, and its function is supported by a dense capillary network [9]. Because of its extensive vascularization and easy accessibility, CAM has been used to study morphofunctional aspects of the angiogenesis process in vivo and the efficacy and mechanism of action of pro- and antiangiogenic molecules [10]. CAM assays have been widely used to 
study angiogenesis [11], and the advantages of the CAM model are as follows: (i) the highly vascularized nature of the CAM greatly promotes the assessment of angiogenic property; (ii) high reproducibility; (iii) simplicity and cost effectiveness; and finally (iv) as the CAM assay is a closed system, the half-life of many new molecules tends to be much longer in comparison to animal models, allowing experimental study of potential angiogenic compounds in small quantities [12,13]. In this study, 1-monocaproin synthesized [14] through a modified process with caproic acid, glycidol, and chromium (III) chloride as a catalyst, was evaluated for a potent angiogenic compound along with VEGF (positive control) and dimethyl sulfoxide (DMSO) (negative control) through the CAM assay.

\section{Materials and Methods}

\section{Synthesis of 1-monocaproin}

Charged $\mathrm{n}$-hexanoic acid kept in the $250 \mathrm{~mL}$ round-bottom flask in the reflux condenser was heated to $60^{\circ} \mathrm{C}$ along with the catalyst, prepared using hexanoic acid (HA) and chromium (III) chloride hexahydrate (1:2 mol ratio), with toluene as the solvent, with continual stirring for $30 \mathrm{~min}$. To this, glycidol was added slowly dropwise at $90^{\circ} \mathrm{C}$, and the reaction mass was maintained at $80-85^{\circ} \mathrm{C}$ for another $120 \mathrm{~min}$. The completion of the reaction was monitored by thin-layer chromatography (TLC) using the mobile phase ethyl acetate-hexane (6:4) and extracted with ethyl acetate. The organic layer was dried with sodium sulfate and concentrated under vacuum.

The products of glycidol reaction, 1-monocaproin (hexanoic acid product, HAP), HA, glycidol, and a coarse material (mixture of all), were characterized by TLC using chloroform/acetone/methanol $(95: 4.5: 0.5 \mathrm{v} / \mathrm{v} / \mathrm{v})$ as the mobile phase. TLC was carried out on a silica gel plate that was activated in the oven at $150^{\circ} \mathrm{C}$ for $30 \mathrm{~min}$ before use. Sample of $200 \mu \mathrm{L}$ of each was developed on TLC plates in mobile phase, and after drying, the bands were located by viewing under $254 \mathrm{~nm}$ of UV light.

\section{Angiogenesis assay using chick CAMs}

CAMs of 7- to 9-day-old fertilized white Leghorn chicken eggs procured from Tamil Nadu Veterinary and Animal Sciences University, Chennai, India, were used for the assay according to a method reported previously [15]. The fertilized eggs were set upright and incubated at $37^{\circ} \mathrm{C}$. After 10 to 11 days of incubation, a window $\left(10 \mathrm{~cm}^{2}\right)$ was made in the eggshell overlying the air sac, and the CAM was exposed in each egg. Implant disks of $3 \mathrm{~mm}$ in diameter were made of filter paper loaded with the compounds to be tested and carefully inoculated at the junction of two blood vessels of the CAM. 1-Monocaproin was then tested at dosages of $1,000(1 \mathrm{mg}$ in $1 \mathrm{~mL}$ of $0.2 \%$ of DMSO), 750,500 , and $250 \mathrm{ppm}$. Then the window was sealed, eggs were incubated, and the grafts were recovered after an incubation time of $72 \mathrm{~h}$. The grafts were then scored for growth and vascularization on a 0 to 4 scoring basis. A positive control VEGF, which is a potent angiogenic inducer, and a negative control DMSO were also tested simultaneously at $1,000 \mathrm{ppm}$ to compare the angiogenic activity of the synthesized compound.

\section{Results and Discussion}

The synthesis of 1-monocaproin was achieved with the catalyst content of $1 \%$ by mass of charged reactants, and at $90^{\circ} \mathrm{C}$, yield achieved was $65 \%$ in $180 \mathrm{~min}$. 1-Monocaproin synthesized with the reaction of glycidol by chromium-caprylic fatty acid complexes changes the nature

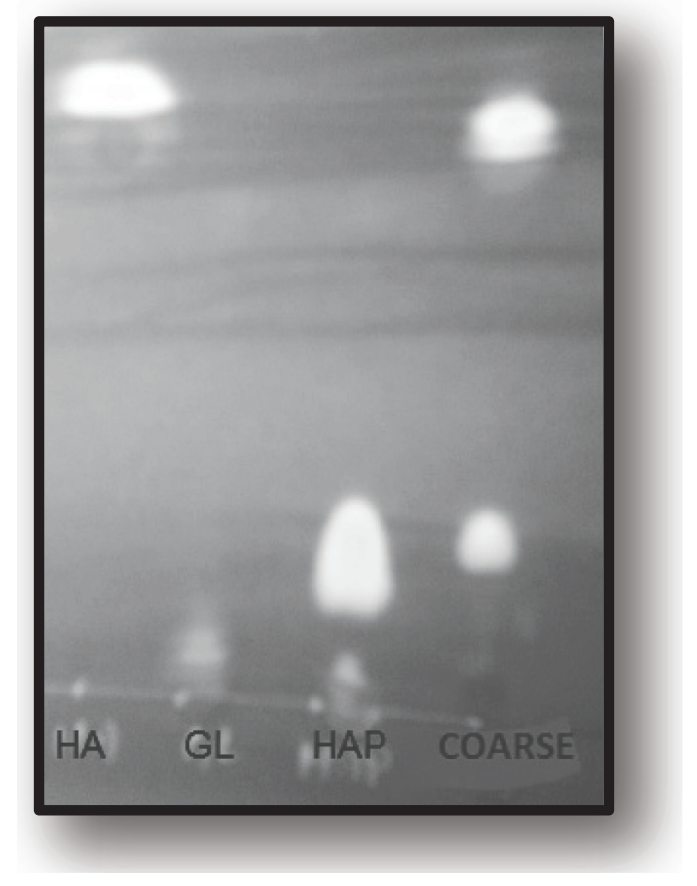

Figure 1: TLC picture of 1-monocaproin (HAP), hexanoic acid $(\mathrm{HA})$, glycidol, and a coarse material (mixture of all)

of the caprylic acid from lipophilic to amphiphilic. The products of glycidol reaction, 1-monocaproin (HAP), HA, glycidol, and a coarse material (mixture of all), were characterized by TLC as shown in Figure 1 , which confirmed the formation of 1-monocaproin and its yield.

The CAM assay has been shown to be a suitable in vivo model including many mechanisms relevant for physiological and pathological angiogenesis [16]. It was further demonstrated that different modifications of the CAM assay are versatile tools for the in vivo evaluation of small quantities (1-2 $\mathrm{mg}$ ) of natural compounds or newly synthesized compounds, enabling the detection of possible angiogenic or antiangiogenic effects of the test compound to evaluate its property as an anticancer or angiogenic drug candidature $[17,18]$. Hence, the CAM assay has been found to be a most suitable tool to test 1-monocaproin at the dosages of $1,000(1 \mathrm{mg}$ in $1 \mathrm{~mL}$ of $0.2 \%$ of DMSO), 750, 500, and $250 \mathrm{ppm}$.

1-Monocaproin at different concentrations, along with VEGF as a positive control and DMSO as a negative control, was tested in the CAM assay for its angiogenic activity, evaluated by a score system as per Table 1 , and the results of the scoring based on growth and vascularization are given in Table 2. The positive control VEGF showed the highest score, 4 , wherein the granuloma was strongly vascularized and a strong starlike network of capillaries was formed around the granuloma. Among the different dose levels tested for 1-monocaproin, the dose was found to be equivalent to VEGF at a 1,000 ppm concentration. Dosedependent activity was observed with 1-monocaproin on the formation of angiogenesis. The angiogenesis effect of 1-monocaproin and the controls are shown in Figure 2.

After $72 \mathrm{~h}$ of incubation (see Figure 2), VEGF treatment led to a simulation with a strong network of sprouting capillaries and increased 


\begin{tabular}{|c|c|c|}
\hline Score & Category & Effects observed \\
\hline 4 & Strong & $\begin{array}{l}\text { The granuloma is strongly vascularized } \\
\text { A starlike network of capillaries is formed around the } \\
\text { granuloma }\end{array}$ \\
\hline 3 & Medium & $\begin{array}{c}\text { The granuloma is vascularized at medium level } \\
\text { A medium starlike network of capillaries is formed } \\
\text { around the granuloma }\end{array}$ \\
\hline 2 & Weak & $\begin{array}{c}\text { The granuloma is weakly vascularized } \\
\text { A thin starlike network of capillaries is formed around } \\
\text { the granuloma }\end{array}$ \\
\hline 1 & Very weak & $\begin{array}{l}\text { The granuloma is somewhat smaller than in catego- } \\
\text { ries } 1 \text { and } 2 \text { and only poorly vascularized } \\
\text { The starlike network of vessels is hardly recognizable }\end{array}$ \\
\hline 0 & No effect & $\begin{array}{l}\text { No effect and no capillary growth } \\
\text { The network of vessels is normal (as the control) }\end{array}$ \\
\hline
\end{tabular}

Table 1: Score values for the evaluation of the angiogenic effect on the chorioallantoic membrane of the fertilized hen's eggs

\begin{tabular}{|c|c|}
\hline Test compounds & $\begin{array}{c}\text { Budding of blood vessels and } \\
\text { vascularization score }\end{array}$ \\
\hline 1-Monocaproin $(1,000 \mathrm{ppm})$ & 3.67 \\
\hline 1-Monocaproin $(750 \mathrm{ppm})$ & 2.33 \\
\hline 1-Monocaproin $(500 \mathrm{ppm})$ & 0.67 \\
\hline 1-Monocaproin $(250 \mathrm{ppm})$ & 0.33 \\
\hline Positive control (VEGF) & 4 \\
\hline Negative control (DMSO) & 0 \\
\hline
\end{tabular}

Values represent the average of triplicate samples $(n=3)$.

Table 2: CAM assay scores of vascularization and budding of blood vessels of 1-monocaproin and the control samples
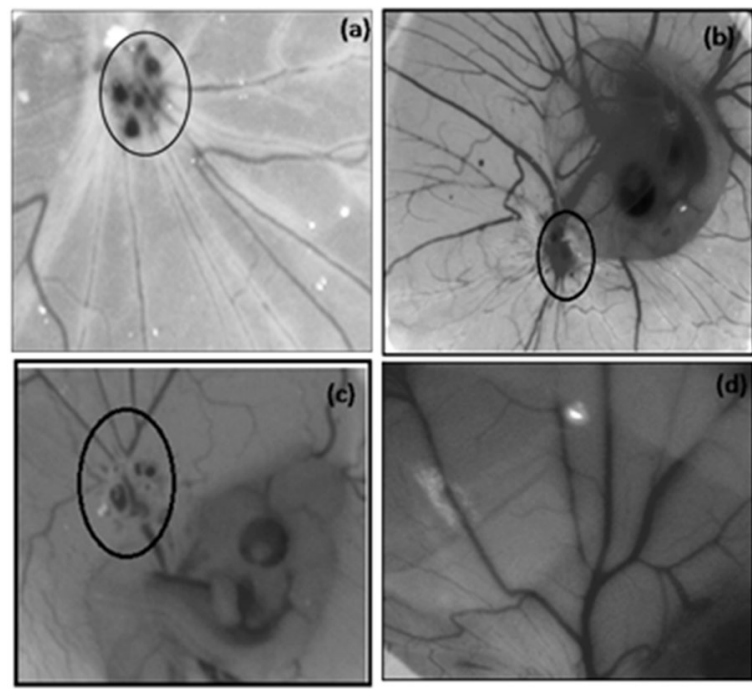

Figure 2: HET-CAM assay: (a) shows the budding of blood vessels by VEGF at 1,000 ppm with a strong network of capillaries (positive control); (b) shows the budding of blood vessels of 1-monocaproin at 1,000 ppm with a strong network of capillaries; (c) shows the budding of blood vessels by 1-monocaproin at the concentration of $750 \mathrm{ppm}$ with a weak to medium network of capillaries; (d) shows no capillary growth with DMSO (negative control) vessel density within the ring, and treatment with 1-monocaproin at the dose level of 1,000 ppm showed the formation of capillaries similar to the VEGF. No changes in vascular structure or density were observed with DMSO. One could speculate that 1-monocaproin activated the VEGF-induced biological effects on endothelial cells by stimulating the growth factor receptor interaction. VEGF is a critical endogenous proangiogenic factor that binds and activates VEGF receptor to induce angiogenesis, mitogenesis, and chemotaxis in endothelial cells. In this study also, exogenous VEGF significantly enhanced the neovascularization in the positive control groups as compared with the DMSO-treated group, evidencing its proangiogenic activity. Similarly, 1-monocaproin also exhibited neovascularization as that of VEGF. In addition, in the treatment group, a significant dose-dependent stimulation of the neovascularization was evident, evidencing its angiogenic property.

Angiogenesis, the generation of new capillaries, is a highly restricted, regulated, and self-limited activity in the healthy adult organism. The fact that pathological angiogenesis can be modulated by molecules of exogenous origin is a fast gaining credence and merits further investigation. In the present study, the CAM assay revealed that 1-monocaproin induced angiogenesis for the first time, and to conclude, the angiogenic property was best exhibited for the 1-monocaproin synthesized thorough the reaction of glycidol by the chromium-caproic fatty acid complex. The results showed that the activation of angiogenesis by 1-monocaproin is due to the stimulation of vascular endothelial cell growth, migration, and angiogenesis at a very low dose. The search and discovery of novel angiogenesis are likely to provide hope to the millions of sufferers of chronic disease and postsurgical recoveries. This work suggests that this synthesized product could be considered as a useful source of material for human health as an angiogenic agent. Because 1-monocaproin is amphiphilic in nature and Generally Regarded as Safe and (GRAS), it could be a potent drug candidature targeting coronary artery disease, stroke, chronic wound, and wound-healing formulations in combination with the existing active drug molecules. However, the underlying molecular mechanism by which 1-monocaproin stimulates the VEGF-induced neovascularization requires further studies.

\section{Acknowledgment}

We thank Bioneemtec India Private Limited, Golden Jubilee Biotech Park for Women Society, Siruseri, Chennai, India, for their facility and support.

\section{References}

1. Carmeliet P (2003) Angiogenesis in health and diseases. Nat Med 9: 32-37.

2. Vinoth Prabhu V, Gopal V (2011) Evaluation of angiogenesis potential of Terminalia bellirica roxb. By Chick Chorio-Allantoic Membrane (CAM) assay Int J Drug Dev Res 2: 256-264.

3. Yin-Shan NG, Patricia Amore AD (2001) Therapeutic angiogenesis for cardiovascular disease. Current Control Trials Cardiovasc Med 2: 278-285.

4. Wadhwa S (2000) Therapeutic myocardial angiogenesis: a ray of hope for patients unsuitable for CABG/PTCA. J Indian Acad Clin Med 1: 252-255.

5. Judah $F(1998)$ Therapeutic angiogenesis in ischemic limbs. Circulation 97 1108-1110.

6. George Pantely A, John Porter M (2000) Therapeutic angiogenesis: time for the next phase. J Am Coll Cardiol 36: 1245-1247.

7. Frater-schroder M, Risau W, Hallmann R, Gautschi P, Bohlen P (1987) Tumor necrosis factor type alpha, a potent inhibitor of endothelial cell growth in vitro, is angiogenic in vivo. Proc Natl Acad Sci USA 84: 5277-5281. 
Citation: Maheswari P, Revathi K (2017) Evaluation of Angiogenic Potential of 1-Monocaproin Using Chick Chorioallantoic Membrane Assay. Biol Med (Aligarh) 9: 401. doi: 10.4172/0974-8369.1000401

Page 4 of 4

8. Dvorak HF, Harvey VS, Estrella P, Brown LF, Mcdonagh J, et al. (1987) Fibrin containing gels induce angiogenesis implications for tumor stroma generation and wound healing. Lab Invest 57: 673-686.

9. Ribatti D, Nico B, Crivellato E, Roccaro AM, Vacca A (2007) The history of the angiogenic switch concept. Leukemia 21: 44-52.

10. Sri Devi M, Vinothini K, Veronica Shalini M, Krishnamoorthy M, Dharini S, et al. (2013) Angiosuppresive activity of Leucas aspera (Willd) Linn. using Chicken Chorioallantoic Membrane (CAM) assay. Int J Innov Res Sci Eng Technol 11: 6327-6333.

11. Richardson M, Singh G (2003) Observations on the use of the avian chorioallantoic membrane (CAM) model in investigations into angiogenesis. Curr Drug Targets Cardiovasc Hematol Disord 3: 155-185.

12. Tufan AC, Atiroglu-Tufan NL (2005) The chick embryo chorioallantoic membrane as a model system for the study of tumor angiogenesis, invasion and development of anti-angiogenic agents. Curr Cancer Drug Targets 5: 249-266.
13. Cimpean AM, Ribatti D, Raica M (2008) The chick embryo chorioallantoic membrane as a model to study tumor metastasis. Angiogenesis 11: 311-319.

14. Janis R, Krejci J, Klasek A (2000) Preparation of 1-monoacylglycerols from glycidol and fatty acids catalyzed by the chromium(III)-fatty acid system. Eur Lipid Sci Technol 102: 351-354.

15. Jain RK, Schlenger K, Hockel M, Yuan F (1977) Quantitative angiogenesis assays: progress and problems. Nat Med 3: 1203-1208.

16. Ribatti D (2008) Chick embryo chorioallantoic membrane as a useful tool to study angiogenesis. Int Rev Cell Mol Biol 270:181-224.

17. Domenico R, Angelo V, Luisa R, Franco D (1996) The chick embryo chorioallantoic membrane as a model for in vivo research on angiogenesis. Int J Div Biol 40: 1189-1197.

18. Spielmann H, Liebsch M, Moldenhauer F, Holzhutter HG, Bagley DM, et al. (1997) CAM based assays. Food Chem Toxicol 35: 39-66. 